\title{
O SIGNIFICADO CURRICULAR DA EDUCAÇÃO COMPARADA
}

\section{REJANE DE MEDEIROS CERVI}

Doutora em Educação Comparada Professora Titular do Departamento de Planejamento e Administração Escolar da UFPR.

Por ocasião do II Seminário Nacional de Educação Comparada, realizado em outubro de 1984, em Brasília, sob a égide da Sociedade Brasileira de Educação Comparada - SBEC, tivemos oportunidade de apresentar a Conferência "A contribuição da Educação Comparada para os estudos de atualização da formação do educador brasileiro". Hoje, retomamos aquela reflexão, com especial atenção ao que se refere à dimensão pedagógica da área de estudo da Educação Comparada, com o particular intuito de sintonizar as expectativas institucionais em relação à respectiva proposta programática no contexto curricular dos cursos de Pedagogia e de Mestrado em Educação da Universidade Federal do Paraná.

Dividimos, este artigo, basicamente, em dois momentos: o primeiro, quando redescrevemos, de forma simplificada, a evolução institucional-pedagógica da Educação Comparada; o segundo, quando alinhavamos a relevância da Educação Comparada enquanto subsídio formativo do profissional da educação, cuja força reconhecemos como decisiva para embasar a negociação dos estudos comparativos no contexto universitário na atualidade. 


\section{A evolução institucional da Educação Comparada: o marco pedagógico.}

A Educação Comparada - EC, enquanto matéria de ensino, remonta ao começo do presente século. DEBESSE e MIALARET (1972) ', relacionam I.L. KANDEL (Manchester, 1905), SANFORD e MONROE (USA, 1905), F. CLARK (Southampton, 1905), LE CAP e MC GILL (Canadá, 1912 e 1925, respectivamente), S. HESSE (Varsóvia, 1920), e F. SCHNEIDER (Salzbourg, 1925), como os primeiros professores de Educação Comparada no mundo.

Com conteúdo essencialmente baseado em paralelos descritivos sobre a "educação estrangeira", o ensino da EC privilegiou, em seu início, os estudos sobre os sistemas educacionais ocidentais europeus e norte-americano.

Naturalmente, a evolução do ensino de EC acompanhou o desenvolvimento teórico dos estudos comparativos. LOURENÇO FILHO (1961) ${ }^{2}$ destaca o trabalho pioneiro da elaboração teórica nas universidades. Nos Estados Unidos, o International Institute of Education da Universidade de Colúmbia, em Nova York, organizado e dirigido por ISAAC KANDEL, manteve uma biblioteca especializada e editou o prestigiado "Educational Yearbook of International Insitute of Teachers College". A difusão de informação sobre a educação nos países foi acompanhada por uma progressiva orientação metodológica de sentido interpretativo filosófico sob responsabilidade do mesmo Kandel. Aliás, Lourenço Filho reconhece a influência do "International Institute" sobre deliberação firmada em 1931, pela "Federação Mundial de Associações de Educação", no Congresso de Denver, a qual indicou a inclusão de "elementos de educação comparada" nos cursos pedagógicos das universidades norte-americanas.

De forma similar, o Institute of Education da Universidade de Londres, através do trabalho de NICHOLAS HANS e JOSEPH LAUWERYS, desenvolveu pesquisa sistemática comparativa, publicando, a partir de 1932, um anuário à semelhança do "International Institute da Universidade de Columbia". Mas LOURENÇO 
FILHO ressalta a orientação metodológica diversa existente entre as duas publicações, o que não impediu a sua fusão posterior.

A organização de um "Museu escolar internacional" sob a iniciativa de F.J. NIELMANN, em Mogúncia, na Alemanha, bem como o lançamento da Revista Internacional de Educação, também neste país, corroboraram para o impulso dos estudos comparativos nesta primeira metade de século. Lourenço Filho atribuiu, ainda, aos educadores alemães ERNST KRIEK e A. FISCHER, a denominação educação comparada, cuja acepção tinha que ver com o sentido de "ciência geral da educação" em contraposição à expresão francesa pedagogia comparada, cujo significado ligava-se principalmente ao "estudo social da educação".

Por último, Lourenço Filho cita o Centro de estudos de legislação comparada do ensino, órgão do Ministério da Educação italiano, que publicou uma revista especializada, como mecanismo que favoreceu a elaboração teórica da EC.

Porém, o progresso teórico derivado destas instituições ligadas às universidades não foi exclusivo. Outras organizações, que não as universitárias, produziram "teoria comparativa". O Bureau Internacional de Educação, a UNESCO, a OCDE, as Sociedades Nacionais de Educação Comparada constituem exemplos de primeiríssima importância entre as instituições que nutriram, de forma direta e indireta, os conteúdos do ensino da EC, ampliando-os e conferindo-lhes complexidade metodológica.

O Brasil tem a sua história particular no que diz respeito ao ensino da EC. Neste País, a introdução da Disciplina se deu em 1932, por intervenção de ANISIO TEIXEIRA, nos planos de formação de professores do Instituto de Educação do antigo Distrito Federal. Em 1939, a EC foi ratificada como exigência curricular na Secção de Pedagogia da Faculdade Nacional de Filosofia. Nesta ocasião, a ministração de classes foi delegada ao Professor GUSTAVO LESSA.

É de todo pertinente reproduzir, aqui, a valiosa reconstituição apresentada pela Professora MARIA APARECIDA BORTOLET- 
TO em sua Tese de Livre-Docência, defendida junto à Universidade de São Paulo, em 1972, e cujo objeto foi "a Educação Comparada no Brasil."

Em 1932, lembra a Professora, na oportunidade da criação da Escola de Professores no Distrito Federal pelo Decreto 3.810, Anísio Teixeira anunciava uma profunda renovação nos métodos de formação de professores, inspirada na organização dos "Teachers College" americanos. A EC aparece, então, não como matéria discriminada e avulsa, mas como integrante da "secção" ou área da Administração Escolar, em uma primeira instância, e na mesma secção de História e Filosofia da Educação ${ }^{3}$.

Este plano de formação de professores do antigo Instituto de Educação do Distrito Federal refletiu-se na organização do Curso ordinário de pedagogia da Faculdade Nacional de Filosofia. Há evidência de correspondência entre aquele plano e a instituição da Cadeira de Administração Escolar e Educação Comparada da 3. ${ }^{\text {a }}$ série deste Curso junto à Faculdade Nacional de Filosofia ${ }^{4}$.

Considerando-se que a organização da Faculdade Nacional de Filosofia, estabelecida pelo Decreto-Lei 1.190, de 04 de abril de 1939, constituiu o padrão normativo para a equiparação dos cursos de Pedagogia no Brasil, à época, tem-se, por esta via, a referência capital para explicar a expansão do ensino da EC em nosso meio.

Bortoletto resgata, ainda, a referência antecedente que faz de SAMPAIO DÓRIA um possível precursor da EC no Brasil. Lembra-nos que, na proposta de criação de uma faculdade de educação (que não se concretizou) no bojo do projeto de reforma do ensino de São Paulo, em 1820, Sampaio Dória incluiu, no $3 .^{\circ}$ ano do curso obrigatório daquela Faculdade, uma disciplina intitulada "Sistemas Antigos e Modernos em Educação", atribuindo, a tal Disciplina ,a finalidade de:

"par a par, o que a respeito tem a humanidade concebido e praticado, expondo com fidelidade e clareza, os sistemas antigos e os sistemas contemporâneos da educação, criticando uns e outros à luz da ciência"'... 
Segundo outros autores, em particular H.C. GONÇALVES ANTUNHA (1967), citado por BORTOLETTO, a atuação de Sampaio Dória sofreu notável influência de RUI BARBOSA. Do que se pode verificar, este legislador nunca deixou de usufruir da perspectiva comparativa em suas argumentações políticas expressas em projetos e pareceres relacionados à educação ${ }^{6}$.

Mas o marco pedagógico da EC no Estado de São Paulo se consolidou quando da instalação da Disciplina no plano dos estudos teóricos da Secção I - Educação, do curso de formação de professores primários do Instituto de Educação "Caetano de Campos" e, também, no último ano dos cursos especiais de formação de professores secundários, com o nome de "Ensino Secundário Comparado", daquele mesmo Instituto, a partir de 1933. Com a criação da Universidade de São Paulo e a respectiva integração do Instituto de Educação "Caetano de Campos" à sua estrutura, em 1934, a EC foi relacionada como 5. Cátedra, combinada à Estatística. A responsabilidade do seu ensino foi submetida ao Professor MILTON CAMARGO DA SILVA RODRIGUES ?

No Estado do Paraná, por força da referida equiparação necessária à Faculdade Nacional de Filosofia, a EC foi introduzida nos planos de estudos da Faculdade de Filosofia, criada em 1938, equiparada em 1939. Compôs o bloco disciplinar da 3. série do Curso de Pedagogia e foi prelecionada pela primeira vez em 1940. A Cátedra foi ocupada nominalmente pelo Professor JOSÉ GOMES RIBEIRO, porém o seu ensino foi atribuído, naquele primeiro ano, ao Professor LAURO ESMANHOTO. Estes dois professores atuaram alternadamente na fase de implantação da Disciplina.

Ademais da instalação da Disciplina, a produção literária na área da EC constitui um dado importante na consideração do estabelecimento curricular deste tipo de estudo. Poder-se-ia dizer, segundo o momento histórico, que esta produção foi causa e ou produto da afirmação da EC enquanto Disciplina.

LOURENÇO FILHO, já citado, nos proporciona a primeira síntese histórica acerca dos estudos comparativos publicados 
no Brasil. Entre 1870 e 1896 destaca JOAQUIM TEIXEIRA MACEDO ("A instrução pública na Prússia", Rio, Tip. Nacional, 1971), MANUEL JOSÉ PEREIRA FRAZÃO ("O ensino público primário na Itália, Suiça, Suécia, Bélgica, Inglaterra e França." Rio, Tip. da Gazeta de Notícias, 1893), AMÉLIA FERNANDES DA COSTA ("O ensino público primário na Itália, França e Bélgica", Rio, Tip. Nacional, 1893) e LEOPOLDINA TAVARES PORTOCARRERO ("O ensino público primário em França, Espanha e Portugal". Rio, Of. do Instituto Profissional, 1896), como autores principais de relatórios sobre os sistemas de ensino no estrangeiro. Realça com o maior entusiasmo, sobretudo, os pareceres sobre o ensino redigidos pelo Deputado RUI BARBO. SA, entre os anos de 1882 e 1883, qualificando esta produção como "o maior ensaio, a esse tempo publicado"8.

A bibliografia mais próxima àquela data, registrada por Lourenço Filho, integra um "Relatório sobre o ensino técnico nos Estados Unidos", escrito e publicado em 1913, em Porto Alegre, por N. VIVALDO COARACI, e uma pequena exposição sobre os processos para a educação de retardados mentais, vigentes em vários países da América Latina, editada em 1917, sob autoria de BASILIO DE MAGALHÃES ${ }^{9}$.

$\mathrm{O}$ aparente isolamento dos educadores brasilerios com relação à educação estrangeira foi rompido, no dizer de Lourenço Filho, pelas manifestações recolhidas por FERNANDO DE AZEVEDO, em inquérito realizado em 1926, as quais se referiam aos movimentos de renovação do ensino fora do País.

A partir daí, e já em fase simultânea à expansão do ensino da EC no Brasil, apresentam importância os trabalhos de ANTONIO CARNEIRO LEÃO, GUSTAVO LESSA, MILTON CAMARGO DA SILVA RODRIGUES, ISAIAS ALVES, FERNANDO DE AZEVEDO, JOSÉ QUERINO RIBEIRO, ANISIO TEIXEIRA, NAIR FORTES ABU-MERHY e MARIANA CRUZ, entre outros. Os numerosos estudos divulgados pela Revista Brasileira de Estudos Pedagógicos, pelos Boletins da Universidade de São Paulo e do Centro Brasileiro de Pesquisas Educacionais e pelo Centro Latino-Americano de Pesquisas em Ciências Sociais igualmente deram 
corpo aos conteúdos da Disciplina de EC. Todavia, entre todo o acervo conhecido, a obra Educação Comparada. Tendências e organizações escolares, de Milton Camargo da Silva Rodrigues, editada em São Paulo, pela Companhia Editora Nacional, em 1938, é considerado como "o primeiro ensaio de exposição geral" sobre a EC no Brasil ${ }^{10}$.

\section{A evolução institucional da Educação Comparada: a institucionalização pedagógica.}

A uniformização dos currículos pelo padrão de Faculdade Nacional de Filosofia, protagonizada na vigência do Estado Novo Novo pelo Decreto-Lei 1.190/39, e que, conforme já dissemos, estendeu o ensino da EC a todo o território nacional, foi alterada a partir da Lei de Diretrizes e Bases da Educação Nacional de 1961 (Lei 4024). Em seus artigos 9., alínea "e" e 70, a LDB atribui ao Conselho Federal de Educação a competência de determinar os currículos mínimos que "habilitassem à obtenção de diploma capaz de assegurar privilégios para o exercício da profissão liberal".

Desta forma, em 1962, o egrégio Conselho Federal de Educação, pelo seu Parecer de número 251, interpretando o conceito de "currículo mínimo", fixou os parâmetros programáticos do Curso de Pedagogia pelos quais ficou invertida a condição de obrigatoriedade dos estudos comparativos.

Dois Pareceres mais, do mesmo Conselho, comprometeram o processo de institucionalização da EC no contexto universitário brasileiro: o Parecer 252/69, que fixou o currículo mínimo de Pedagogia e o Parecer 632/69, que definiu o conteúdo específico da Faculdade de Educação.

Irônicamente, ambos Pareceres se serviram da comparação para sustentar suas argumentações, sem, no entanto, reconhecê-la como instrumental analítico fundamental no currículo de Pedagogia. O confronto entre os termos "pedagogia" e "educação" em contextos históricos e culturais distintos, apresentado pelo Relator no Parecer 632, sem dúvida alguma, deu especial brilhantismo à sua exposição. 
Mais significativos, não obstante, foram os efeitos do $\mathrm{Pa}$ recer 252/69, que se fizeram sentir, com toda a sua força, nas medidas de racionalidade econômica que acabaram por reduzir os currículos, na prática, ao mínimo estabelecido em lei. O ensino da EC foi mantido, contudo, nos centros acadêmicos de maior tradição (Universidades públicas mais antigas) e, aleatoriamente, em outras instituições de menor porte e isoladas. Tal manutenção (ou resistência?) refletiu o empenho pessoal de docentes provavelmente inspirados em uma experiência acadêmica privilegiada $\left({ }^{11}\right)$.

Neste processo de institucionalização pedagógica, os estudos comparativos em educação estiveram sediados nas instituições superiores de forma a mais variada: junto à Estatística Educacional, junto à Didática, junto à Administração Escolar e à História e Filosofia da Educação. Esta composição difusa tem explicações casuísticas de cunho pessoal, não chegando a alterar o enfoque essencial do estudo dos sistemas educacionais estrangeiros. A sua presença mais regular, entretanto, ocorreu como extensão da Administração Escolar, em função de que os professores desta Disciplina foram, frequentemente, os principais agentes de importação dos estudos comparativos, especialmente associados às abordagens no campo das políticas nacionais de educação e das estruturas de administração e de ensino. Há de somar-se, pois, aos nomes já mencionados neste texto, os de Antonio Pithon Pinto (Bahia), José Gomes de Campos (Rio Grande do Sul), Paulo de Almeida Campos (Rio de Janeiro), José Querino Ribeiro (São Paulo), Carlos Correa Mascaro (São Paulo), Maria Antonieta Bianchi (Minas Gerais), entre outros, como ilustração desta hipótese explicativa.

Ainda em função do descompromisso parcial do Parecer $252 / 69$, as instituições de ensino superior, de surgimento mais ou menos recente, nem sequer tangenciaram a Disciplina EC, ainda que fosse por uma configuração eletiva, em seus planos de formação de professores e/ou de especialistas em educação.

Todo este encaminhamento de cunho recessivo da EC no Brasil se dá, paradoxalmente, em um momento em que os estu- 
dos comparativos efervescem no seio das organizações internacionais, nos programas de formação dos "experts", e quando se diversifica a pesquisa comparativa nas universidades de todo o mundo, assim como é extremamente denso o intercâmbio de conhecimentos em escala internacional. Aliás, há participação brasileira na própria internacionalização da educação. A atuação do Brasil junto à UNESCO e OEA, por exemplo, merece ser avaliada. Mais remotamente, Lourenço Filho reverencia o desempenho de ALCEU DE AMOROSO LIMA e VIANA MOOG, desde a criação do Conselho Cultural Interamericano, em 1948, e a partir de cuja instalação, em 1951, passou-se a produzir estudos de conjunto sobre as condições da vida científica, educacional e tecnológica no continente americano $\left({ }^{12}\right)$.

Outra iniciativa, de caráter isolado, ocorreu no Brasil e refletiu sobre a EC em nosso contexto. Durante quase uma década (1958-1966), a UNESCO patrocinou um programa de formação de especialistas em educação para a América Latina, cuja realização se deu na sede do Centro Regional de Pesquisas Educacionais "Queiroz Filho", em São Paulo, ensejando uma das mais ricas experiências de ensino da EC, sob a orientação do Professor ANGEL DIEGO MARQUEZ e assistência da Professora M. A. BORTOLETTO.

Mas, se a vocação dos estudos comparativos junto aos programas de formação de professores e especialistas constituiu matéria intimamente relacionada a ânimos de renovação pedagógica, e, por tal sugere importância indiscutível, a sua não adoção como via de regra carece de explicação.

Antes de tudo, diríamos que o prestigiamento normativo-curricular da EC cedeu à dificuldade de uma generalização da prática docente proporcionada pela imposição de certas exigências, tais como: a EC requer qualificação destacada e abrangente em termos culturais e científicos por parte dos docentes; a EC impõe uma atuação interdisciplinar, e, portanto, um trabalho em equipe; a EC supõe apoio documental e bibliográfico importado, volumoso e constantemente atualizado; por isto mesmo, a EC também exige o domínio plural de línguas estrangeiras; a EC sugere um intercâmbio internacional intenso, vivências no Exte- 
rior, inclusive; por fim, há que considerar que a EC, enquanto Disciplina acadêmica, encontra-se em processo de contínua discussão teórica. Sem qualquer exagero, todas estas são barreiras respeitáveis, sobretudo para um sistema universitário modesto, acanhado financeiramente e altamente restringido burocraticamente.

Esta modéstia do sistema educacional brasileiro se opõe, é bem verdade, ao caráter antecipatório que não só cunhou o aparecimento da EC, como se reconhece cunha quase toda a evolução da cultura brasileira. Ou seja, queremos lembrar que a EC foi "matéria de ensino" antes de se consolidar como "área de pesquisa". Estamos longe de concordar, contudo, com que esta antecipação tenha significado, necessariamente, precocidade gratuita. O fato de Milton Rodrigues editar a primeira obra de EC no Brasil apenas cinco anos depois do "clássico" Comparative Education, de Kandel, em 1933, pode significar capacidade de nossos professores de fazer pesquisa, como mínimo, na linha da educação no estrangeiro, o que não deixou de ter clara pertinência naquele momento.

\section{Sobre as bases de negociação dos estudos comparati- vos no contetxo universitário: da relevância formativa da EC.}

Tal como temos podido ver, o exercício da comparação em educação é, ainda no Brasil de hoje, um privilégio de legisladores (o que pode ser um bom ou um mau sinal). Este privilégio, calcado no observação da educação estrangeiı e cujo desempenho tampouco esgota as potencialidades metodológicas da comparação, acaba por competir com o próprio ensino da Disciplina.

Por outro lado, o perfil rarefeito da distribuição dos especialistas em comparação ou docentes nas instituições de ensino superior, não produziu a pressão mínima necessária para a negociação da Disciplina nos processos das prescrições curriculares tramitados até o presente. Portanto, a institucionalização pedagógica da EC está para ser conquistada. Nesta conquista, a 
qüestão da relevância da EC é, em sua definição, a condição básica para a referida negociação da presença da Disciplina no contexto universitário. É, pois, desta relevância que nos ocuparemos a seguir.

Ao projetar a relevância da área de estudo, é prudente optar por um conceito genérico de EC e por uma definição do profissional de educação cuja formação há de suscitar os préstimos de um determinado conteúdo.

Dentro de nosso entendimento, a EC, enquanto área de estudo, transcende as intenções de reconhecimento de perfís de semelhanças e dessemelhanças de realidades educacionais, para tentar lograr explicações mais complexas sobre estas semelhanças e dessemelhanças, sobre as "coincidências" ou "parentesco político" dos sistemas e práticas educacionais, seja em âmbito internacional, intranacional e/ou transnacional, em termos de presente e de futuro.

No que concerne à definição do profissional da educação, recorremos a uma classificação genérica elaborada em função das principais atividades adstritas aos sistemas de formação escolar convencional e para-escolar. Assim, o profissional da educação, na condição de agente social, pode atuar de forma pedagógica estrita, isto é, como formador lou produtor de documentação, de informação, de conhecimentos e de formas de intervenção, preparador desta documentação, tecnólogo; difusor, professor propriamente dito ou orientador) e/ou como administrador da educação (ou político, planejador, legislador, administrador escolar propriamente dito, etc...) $\left({ }^{13}\right)$.

A nosso ver, ainda, as diferentes atuações não são absolutamente hierarquizáveis, de vez que reconhecemos a interação etnre elas e a complexidade moral comum que as afeta. Podemos dizer, mesmo, que as competências técnicas são intercomplementares sobre uma competência política-denominador.

Fundamentados na crença desta complexidade moral comum é que argumentamos a favor de um substrato formativo que instrumente técnica e politicamente a interação de papéis 
especializados. A correspondência entre a competência técnica e a competência política, enquanto julgamento de valor, deve ter precedência sobre qualquer tipo de racionalidade. Neste sentido, o substrato formativo deverá integrar estudos que:

(a) por se constituirem em recurso fundamental nas ativividades de conhecer $\left({ }^{14}\right)$, ampliam a capacidade analítica do profisisonal (recurso do CONHECER);

(b) por condições próprias de conteúdo e de metodologia, favoreçam o rigor científico e a intervenção crítica na adoção de propostas e ações pedagógicas e educacionais, na atualidade e para o futuro (recurso de $\mathrm{DECl}-$ SÃO e MUDANÇA).

Tais valores deixam para trás as intenções ortodoxas de imitação e erudição, implícitas nas comparações vulgares e acríticas, tão usadas (e abusadas) por administradores quanto por "contestadores oficiais", ambos passíveis de serem identificados como colonizadores culturais, ora internos ora externos, ainda que em posições de aparente antagonismo.

As duas dimensões apontadas para o "substrato formativo" são amplamente reconhecidas na literatura de rotina da EC (Ver, a este respeito, HOLMES, ROBINSOHN, KING, TITZ, FURTER, COWEN, MARQUEZ, BOHN...) $\left({ }^{15}\right)$.

Podemos, ainda, demonstrar que a necessidade dos estudos comparativos está legitimada em termos universais, o que não impede que, em algumas realidades (e aqui, a nossa) esta relevância da EC não esteja explicitada ou sequer concordada. Ou, melhor dizendo, existe algo próximo a uma indefinição institucional da área de estudo. Daí um constrangimento, difícil de evitar, em relação a depoimentos do tipo "a EC não existe no Brasil".

Mas, voltando aos termos da negociação da institucionalização da EC no contexto universitário brasileiro, e considerado o quadro de não explicitação da relevância da EC no meio legislativo, resta uma tarefa preliminar que é reafirmar as dimensões prática e crítica que derivam dos valores enunciados 
acima. Para tal reafirmação, vale rever e adaptar o enunciado de ROBINSOHN (1971) ${ }^{16}$.

1. - A EC emprega método intelectualmente rigoroso ao proporcionar explicações sobre o fenômeno educacional. É geralmente aceito que, através da análise comparativa, pode-se chegar a explicações gerais sobre as relações entre a educação e as outras dimensões da vida social, fazendo uso da abordagem intercultural. Seu método desafia as faculdades de imaginação e exercita competência de raciocínio disciplinado e de generalização sistematizada. Sua abordagem pluralista e interdisciplinar acomoda não só a variedade de inclinações e aptidões, mas um vasto campo a ser pesquisado.

2. - A EC sensibiliza a perspectiva sobre a experiência local, nacional e/ou regional, ao mesmo tempo que neutraliza o sentimento etnocêntrico, o convencionalismo, a rotina. Na observação de FURTER (1982) ${ }^{17}$, a atenção dos pedagogos é freqüentemente circunscrita aos limites de uma única experiência, o que pode conduzir a um centrismo radical. Esta visão centrista pode ser tão extremada que a própria consciência do etnocentrismo desaparece pela eliminação da possibilidade de imaginar outras realidades. Do centrismo à expressão de uma "consciência tranqüila por omissão" existe um passo muito estreito.

$3 .^{\circ}$ - A EC desenvolve abordagens, primeiramente, para alcançar uma compreensão das políticas de educação e, em conseqüência, para visualizar alternativas e/ou atitudes de mudança. Este engajamento na transformação social, tão decantado nos plágios literários em nosso cotidiano, constitui uma possibilidade séria e concreta de comprometer os profissionais da educação (individual e coletivamente) pela via, também, da reflexão comparativa. Os estudos comparativos estendem, ainda, o compromisso político da 
educação com a paz e a solidariedade mundial. Não é difícil, aqui, revelar a interface da EC com a Utopia.

$4 .^{\circ}$ - O valor prático da EC se resume, também, pelo sentido de aplicação, quando proporciona o uso crítico de um repertório de planos e soluções culturais, por um lado, e, por outro, quando, pela interpretação, contribui ao aperfeiçoamento de orientação no amplo campo das práticas e instituições educacionais.

5. - A comparação tem, igualmente, uma função heurística, ao proporcionar a identificação das características de uma grande variedade de sistemas particulares; ao situar instituições e processos em relação a modelos conceituais; ao oportunizar esclarecimentos e questionamento de noções e categorias educativas (aliás, Robinsohn afirma que a EC é a única chave que logra atingir tal objetivo); e, finalmente, ao promover a síntese pela identificação das condições sob as quais ocorrem as propostas e as práticas educativas.

4. Sobre as bases de negociação dos estudos comparativos no contexto universitário: da concepção pedagógicocurricular da EC.

Muito embora, em nossa opinião, a situação "ensino-aprendizagem" se revista de um caráter circunstancial, existe uma intencionalidade maior, subjacente a toda intervenção pedagógica que deve ser explicitada.

Estimamos como viável propor uma alternativa pedagógica para a EC, enquanto matéria de ensino, com base nos valores que foram filtrados, e considerando, inclusive, a fase de autoanálise e articulação metodológica que caracteriza os estudos comparativos. Esta alternativa está concebida em função dos seguintes pressupostos:

I - A EC precisa ser encarada como abordagem metodológica de contextualização do problema educacional em realidades distintas e simultaneamente. 
II - Esta contextualização simultânea do problema educacional deve considerar a projeção de esferas analíticas que se interpenetram, a saber:

(a) esfera pedagógica, quando se há de proporcionar a inserção crítica do problema educacional, observado nos contextos pedagógicos ou na dimensão técnica;

(b) esfera institucional, quando se há de proporcionar a inserção crítica do problema educacional, observado no contexto da multifuncionalidade formativa ou na dimensão sócio-política da educação;

(c) esfera social mais ampla, quando se há de proporcionar a inserção crítica do problema educacional, observado no contexto das exigências e contradições sociais contemporâneas em sua total amplitude ou dimensão cosmológica.

III - As esferas de contextualização do problema educacional não excluem, todavia, a noção de autonomia relativa da ação educacional, mesmo porque não se poderia desconsiderar que a educação também prepara para a mudança (dimensão cultural divergente da ação de educar). A EC, pela revelação que a sua metodologia pode propiciar, há de ratificar o dizer de SNYDERS (1976) para quem é esta prática divergente que confere à instituição educacional uma propriedade de "ambiguidade criadora": a escola, ao mesmo tempo que é conservadora e reprodutora, constitui uma ameaça ao conservantismo e às situações estabelecidas ${ }^{18}$.

Por todas estas pretensões analítico-metodológicas a EC se diferencia das disciplinas de fundamentação científico-pedagógica e das disciplinas instrumentais no conjunto tipológico das atividades e abordagens formativas que integram o processo de profissionalização do professor e do especialista em edu- 
cação. As primeiras representam as fontes teóricas da ação de educar e podem ser desmembradas em "disciplinas subsidiárias das ciências da educação" (Psicologia, Filosofia, Sociologia, Antropologi a, História,....) e "disciplinas aplicadas à educação" (Psicologia Educacional, Filosofia da Educação, Sociologia da Educação, Antropologia Educacional, História da Educação...). As segundas, englobam a linguagem e os mecanismos auxiliares que movimentam a prática educativa em si e igualmente se desdobram em áreas gerais (Estatística, , Métodos e Técnicas de Pesquisa, Administração e Supervisão, Didática,....) e específicas (Estatística aplicada à Educação, Métodos e Técnicas de Pesquisa em Educação, Métodos de Administração e Supervisão Escolar, Métodos de Orientação Educacional e Vocacional, Práticas de Ensino, Tecnologia Educacional,...).

Podemos aceitar, que a EC, em sua conotação de estudo de contextualização, situa-se ao lado de áreas de estudo como Estrutura e Funcionamento do Ensino, Currículos, Legislação do Ensino... Porém, ela pode ser apreciada como a meta-disciplina das abordagens de contextualização, de vez que ela pode chegar, pelo confronto, à síntese analítica de todas as práticas educacionais em contextos múltiplos.

Didaticamente, os conteúdos da EC comportam estudos chamados de área (estudo de sistemas educacionais locais, regionais e nacionais), estudos de problemas educacionais, estudos comparativos propriamente ditos, estudos das relações internacionais no campo da educação e seus sub-produtos (transferência em educação, dependência, cooperação internacional, inovação,...) e, natural e necessariamente, a própria revisão epistemológica da EC, enquanto segmento teórico. Em qualquer dos conteúdos da EC, é pronunciada a dimensão política das abordagens.

Frente a tal abertura do repertório e das regras de comparação, o que fazer da EC no Curso de Pedagogia ou no Curso de Mestrado em Educação, estratégias tradicionais de formação inicial e continuada do profissional da educação? Que programa desenvolver? 


\section{Sobre o significado curricular da EC: síntese de expectativa.}

Responder à questão anterior impõe o retomar a preocupação da EC para com a sensibilização face ao diferente e ao semelhante, face ao caráter aparente destas diferenças e identidades, para com a revelação do parentesco das idéias e das práticas pedagógicas e educacionais, para o despertar do reconhecimento do divergente viável e desejável, para com o tratamento cautelar das transposições e generalizações impróprias e injustas...

Finalmente, "ensinar" EC é usar dialogicamente da comparação para melhor conhecer, melhor se posicionar, melhor interpretar a viabilidade do singular, melhor julgar e combater as contradições, e mais fortemente chegar ao comportamento solidário pela via educacional. refletir...

O repertório para lograr estas regras? Um novo capítulo a

\section{REFERÊNCIAS BIBLIOGRÁFICAS}

1. Debesse, M. y MiAlaret, G. Pedagogía Comparada, Barcelona, OikosTau, 1974: 22.

2. LOURENÇO FILHO, M.B. Educação Comparada. São Paulo, Melhoramentos, 1961: 24 .

3. BORTOLETTO, Maria Apparecida. EDUCAÇÃO Comparada: subsídios para seu estudo no Brasil. Tese de Doutorado, Universidade de São Paulo, 1972: 45 e segs.

4. Op. cit.: 53.

5. Op. cit.: 49.

6. Op. cit.: 49.

7. Op. cit.: 56 .

8. LOURENÇO FILHO, op. cit.: 30 .

9. Op. cit.: 30 .

10. Op. cit.: 31 .

11. A respeito da oferta de EC junto ao ensino superior brasileiro, a Sociedade Brasileira de Educação Comparada - SBEC, vem desenvolvimendo pesquisa histórica, sob a coordenação da Professora MABEL TARRE CARVALHO DE OLIVEIRA. 
12. LOURENÇO FILHO, op. cit.: 30 .

13. FURTER, Pierre. Le planificateur et l'éducation permanente. Paris, UNESCO, 1977.

14. LOURENÇO FILHO, op. cit.: 15.

15. ROBINSHON, op. cit.; TITZ, J.P. L'Education Comparée, peut-elle avoir une valeur operationelle? L'experience des organisations internacionales. Genève, CESE, 1981; FURTER, P. op. cit.; COWEN, Robert. The place of comparative education in the educational sciences. Genève, CESE, 1981; MARQUEZ, Angel Diego. Educación Comparada. Teoría y metodología. Buenos Aires, El Ateneo, 1972;

16. ROBINSOHN, S.B. "The relevance of Comparative Education for Teacher Training". In Kappa Delta Pi Record. V.8, 1971: 4-7.

17. FURTER, Pierre. Os sistemas de formação em seus contextos. Introdução e um método de educação comparada. Rio de Janeiro, Fundação Getúlio Vargas, 1982:

18. SNYDERS, George. Ecole, classe et lutte des classes. Paris PUF, 1976:21. 